\title{
Comparative Study of Clinical Manifestation, Plain Film Radiography and Computed Tomography for Diagnosis of Maxillofacial Trauma
}

\author{
Amit Goel \\ Associate Professor Surgery, Jamia Hamdard Medical College, New Delhi, India \\ Email: gamit11@rediffmail.com \\ Received 22 August 2015; accepted 17 October 2015; published 20 October 2015 \\ Copyright (C) 2015 by author and Scientific Research Publishing Inc. \\ This work is licensed under the Creative Commons Attribution International License (CC BY). \\ http://creativecommons.org/licenses/by/4.0/ \\ (c) () Open Access
}

\begin{abstract}
Objective: Maxillofacial injuries are one of the commonest injuries encountered. Roentgenographic evaluation of maxillofacial trauma is of prime importance for diagnosis and treatment of these injuries. Study Design: Forty patients were evaluated in the prospective four-year study. We studied and evaluated the demography and diagnostic efficacy of clinical, plain radiography, and computed scan in maxillofacial trauma. Result: Road traffic accidents were the commonest cause of maxillofacial injuries. Patients having multiple fractures, mandibular fractures were the commonest. Conclusion: Computed tomography proved a useful adjunct in midfacial trauma.
\end{abstract}

\section{Keywords}

\section{Maxillofacial, Clinical, Radiography, Computed Tomography}

\section{Introduction}

Roentgenographic evaluation of maxillofacial trauma is integral component in management of acutely injured patient. Urbanisation and increase in vehicular traffic, road traffic accidents are main causes of maxillofacial injuries. CT scan has enhanced fine imaging of facial trauma. Computed tomography for clinical diagnosis was described by house field in 1973 [1]. In our study of maxillofacial trauma, we studied the spectrum of maxillofacial injuries. The role of clinical examination, plain film radiography, CT scan in diagnosis of facial fractures was studied.

\section{Material and Methods}

Patients having facial trauma were evaluated in emergency department of our hospital. A detailed clinical ex-

How to cite this paper: Goel, A. (2015) Comparative Study of Clinical Manifestation, Plain Film Radiography and Computed Tomography for Diagnosis of Maxillofacial Trauma. Modern Plastic Surgery, 5, 47-49. 
amination was prelude to radiological evaluation of patient. A Complete and lucid past and present history with particular emphasis on symptoms, inebriation was taken. This was followed by a thorough clinical examination including local and systemic examination. An examination of facial structure was accomplished progressing from superior to inferior. All signs were noted like swelling, limitation, edema, bleeding, diplopia, tenderness, malocclusion, echymosis, hypoesthesia and crepitus. Thorough ENT and opthalmic, neurosurgical examination was done. Plain film radiography was done with film transversely and longitude nally in congruity with projection envisioned. Views acquired were

1) Occipital-mental $45 \mathrm{PA}$;

2) Lateral view;

3) Occipitofrontal.

All patients of facial trauma were subjected to X-rays and computed tomography.

\section{Results}

Forty cases were studied. There were 27 males and 13 females. The commonest age group was between 20 - 29 years. Road traffic accidents were commonest causes of maxillofacial trauma comprising of 15 cases. With the advent of urbanization, vehicular accidents were the commonest cause of maxillofacial trauma. Physical assault was another cause of maxillofacial injuries comprising of 7 cases. Labourers and farmers accounted for maximum number of cases. Alcohol, hearing impairment were predisposing factors but were not significant. Deformity and pain were the commonest symptoms. Mandibular fractures were the commonest fractures comprising of 32 cases. There were 16 cases of maxillary fractures. Majority of patients had multiple injuries. Patients were subjected to clinical examination after admission, and regular examination was done during subsequent days. CT scan, X-rays were done after clinical examination. Clinical and X-ray were comparable in different facial fractures but CT scan proved better in midfacial and deeper facial bones.

\section{Discussion}

Facial injuries are caused by accidents and physical assaults advocated by Shanks and Killey [2]. Rose and Killey mentioned assaults as commonest cause [3]. Keats said that facial architecture is divided by areas of resistance [4]. Finkle compared clinical and radiological diagnostic accuracy and found that nasal bone, supraorbital rim and infraorbital rim were diagnosed by clinical examination [5]. CT scan was found to be better in diagnosis of facial fractures except superficial median structures [6]. Zilka compared CT scan with conventional radiography in 30 patients of facial fractures. Six cases were missed by conventional radiography which was diagnosed by CT scan [7].

The ability of CT scan to simultaneously depict both osseous and soft tissue structures expands the role that diagnostic radiology plays in evaluation of facial fractures [8]. Two and three dimensional CT scan were used for evaluation of maxillofacial trauma. Three dimensional CT scan demonstrates spatial relationships not easily conceptualized by two dimensional CT scan but was time consuming and had limited resolution. Fracture fragments and associated skeletal deformities are clearly identified by CT scan permitting the diagnosis of zygomatic, orbital, naso-ethymoid, temporal, frontal and mandibular fractures. Complex fractures with fragmentation are easily identified on CT scan than conventional tomography because of superior contrast resolution of computed tomography. Advantages of computerized tomography are lack of image superimposition, preservation of detail of soft tissues, enhancement of vascular tumors, and selective enlargement of areas of interest. Presence of any metallic artifacts, limits the use CT scan [9].

In our study we too encountered patients with firearm injuries who had metallic pellets embedded in face. It causes splaying of rays which are called streak effect.

Smith et al. described facial fractures frequency, injury characteristics, diagnosis by retrospective study. Fractures were frequently present in orbit 32\%, malar and maxilla $26 \%$ and nasal bones $19 \%$ [10]. Maliska et al. described 185 maxillofacial fractures and found that mandible was commonest fracture $54.6 \%$, followed by zygoma 27.6\%. Commonest age of maxillofacial fractures was 18 - 39 years [11].

\section{Conclusion}

Imaging for maxillofacial injuries serves as principal means for qualifying the clinical diagnosis. It helps in planning the treatment and comprehensive surgical repair. Facial trauma is complex injuries of body and must 
need for accurate, complete diagnosis. Neglected facial injuries lead to significant deformity, disability. Early identification of clinically occult facial fractures using CT scan leads to appropriate early management, resulting in improved outcome. Maxillofacial injuries should be initially evaluated by thorough clinical examination and plain radiography. In complex panfacial trauma especially in midfacial segment, unenhanced axial and coronal CT scan is a must and should be routinely considered.

\section{References}

[1] Housefield, G.N. (1973) Computerized Transverse Axial Scanning. The British Institute of Radiology, 46, 1016. http://dx.doi.org/10.1259/0007-1285-46-552-1016

[2] (1957) Injuries of Jaw. In: Cochrane, Shanks and Kerley, Eds., Textbook of X-Ray Diagnosis, vol.1 and vol. 2, H. K. Lewis, London, 357-363, 250-265.

[3] Rowe, N.I. and Killey, H.C. (1968) Fractures of Facial Skeleton. E \& S Livingstone Ltd., Edinburgh and London, 638.

[4] Keats, T.E. (1984) Emergency Radiology. Yearbook Publication, Chicago, London, 93-72.

[5] Finkle, D.R., Ringler, S.L., Luttenton, C.R., Beernick, J.H. and Peterson, N.T. (1985) Comparison of Diagnostic Method Used in Maxillofacial Trauma. Plastic and Reconstructive Surgery, 75, 32-41.

[6] Frame, J.W. and Wake, M.J.C. (1982) Evaluation of Maxillofacial Injuries by Use of Computerized Tomography. Journal of Oral and Maxillofacial Surgery, 40, 482-486.

[7] Zilka, A. (1982) Computerized Tomography in Facial Trauma. Radiology, 144, 540-545.

[8] Gentry, L.R., Manor, W.F., Turski, P.A. and Strother, C.M. (1983) High Resolution CT Analysis of Facial Struts in Trauma: Osseous and Soft Tissue Complications. AJR, 140, 533-554.

[9] Demarino, D.P., Steiner, E., Poster, R.B., Katzburg, R.N., Hengerer, A.S., Herman, G.T., et al. (1986) Three Dimensional Computed Tomography in Maxillofacial Trauma. Archives of Otolaryngology-Head and Neck Surgery, 112, 146-151.

[10] Smith, H., Peek-Asa, C., Nesheim D, Nish, A., et al. (2012) Clinical Diagnosis and Characteristics of Facial Fracture at Midwestern Level, Trauma Centre. Journal of Trauma Nursing, 19, 57-65. http://dx.doi.org/10.1097/JTN.0b013e31823a4c0e

[11] Maliska, M.C., Luma Jr., S.M. and Gil, J.N. (2009) Analysis of 185 Maxillofacial Fractures in the State of Santa Catarina Brazil. Brazilian Oral Research, 23, 268-274. http://dx.doi.org/10.1590/S1806-83242009000300008 